\title{
The Effect of Zhong-yong Thinking to Employee Survival Ability-Taking Social Capital as a Mediating Variable and Knowledge Sharing Behavior as a Moderating Variable
}

\author{
Zhang Chun-Yu ${ }^{1 *}$, Chen Chun-Shuo ${ }^{2}$ \\ ${ }^{1}$ Dhurakij Pundit University, China-ASEAN International College, Bangkok, Thailand \\ ${ }^{2}$ Dhurakij Pundit University, China-ASEAN International College, Bangkok, Thailand *email:468160345@qq.com \\ chencs0702@gmail.com
}

This is an open access article distributed under the Creative Commons Attribution License, which permits unrestricted use, distribution, and reproduction in any medium, provided the original work is properly cited.

\section{ARTICLE DETAILS}

\section{Article History:}

Received 02 october 2017

Accepted 06 october 2017

Available online 11 october 2017

\section{Keywords:}

Confucian Culture, Zhong-yong

Thinking, Social Capital,

Knowledge Sharing Behavior

Employee Survival Ability.

\section{ABSTRACT}

\begin{abstract}
Zhong-yong is the core of Chinese Confucian culture. From the point of view of employee survival ability, Zhongyong thinking is multipartite thinking with conformity and concordance. The results of this research are show as follow: The multipartite thinking, conformity and concordance of employees' Zhong-yong thinking have positively significant effects on social capital and employees survival ability; Social capital has positively significant effects on employees survival ability; Social capital plays a partially mediating role between the multipartite thinking dimension, conformity dimension and concordance dimension of employees' Zhong-yong thinking and employees survival ability; Knowledge sharing behavior has positively moderating effects on multipartite thinking of Zhongyong and social capital; Knowledge sharing behavior has no moderating effects on the conformity of Zhong-yong thinking and social capital; Knowledge sharing behavior has no moderating effects on the concordance of Zhongyong thinking and social capital; Knowledge sharing behavior has no moderating effects on social capital and employee survival ability.
\end{abstract}

\section{Introduction}

The management style with oriental culture characteristics has gradually become an important research subject that must be confronted by global theory circles and business circles. Zhong-yong is the core of Chinese Confucian culture, which also takes up the orthodox status of traditional Chinese cultures for long with strong pervasive and penetrating powers. From the perspective of individuals, in order to survive in natural and social realities, individuals must realize the harmony and integration with the nature, others and society. To establish a bridge of harmony, it is necessary to acquire some certain survival abilities. The survival ability is a capacity upon which human beings can survive.

Based on previous theories, the research has adopted the method of empirical analysis, taking enterprise employees as research objects to investigate how the Zhong-yong thinking and social capital have influenced the employee survival ability. In addition, the research tries to verify whether knowledge sharing behavior has jamming effects between Zhong-yong thinking and social capital as well as between social capital and employee survival ability.

\section{Literature review and hypotheses development}

\subsection{Relationship between Zhong-yong thinking and social capital}

Zhang and Gu(2015) believe that Zhong-yong thinking has its features with a harmonious interpersonal coordination where peace is the most precious [1]; Shen(2005) tends to adopt the interpersonal practice of Zhong-yong to establish, maintain, develop and improve own "popularity" status in a group or social circle in specific contexts of direct or indirect communication with others [2]. The favorable "popularity" of individuals in a group or social circle is significant capitals for them to acquire more resources accordingly. Wu and Lin(2005) divide Zhong-yong thinking into three dimensions namely multipartite thinking, conformity and concordance to study the Zhong-yong thinking of individuals [3]. It can be inferred from the above literature that Hypothesis 1 of the research is listed as follows:

H1: Zhong-yong thinking has positive effects on social capital.
H1a: Multipartite thinking has positive effects on social capital.

H1b: The conformity of Zhong-yong thinking has positive effects on social capital.

H1c: The concordance of Zhong-yong thinking has positive effects on social capital.

Li, Zhang and Shang(2013) think that the "people-oriented" concept of Confucian culture has played a positive role in promoting the operation and management of modern enterprises [4]. In their research, they have pointed out that people guide their own thinking and behaviors with harmonious thoughts which will be further internalized into individual value systems. Such an atmosphere and culture spirit can enhance the employee survival ability. In the research of Li and Chen(2016), Zhongyong thinking has an obviously positive correlation with social adaptation and has positively significant effects on it [5]. It can be inferred from the above literature that Hypothesis 2 of the research is listed as follows:

H2: Zhong-yong thinking has positive effects on employees survival ability.

H2a: Multipartite thinking has positive effects on employees survival ability.

H2b: The conformity of Zhong-yong thinking has positive effects on employees survival ability.

H2c: The concordance of Zhong-yong thinking has positive effects on employees survival ability.

\subsection{The mediating role of social capital}

Burt(1992) thinks that social capital, which can provide information and resources, is propitious to collect and transmit information. Meanwhile, it has been proved that social capital can offer more bonus and promotion opportunities for managers in the relational network [6]. Nahapiet and Ghoshal (1998) believe that social capital is a resource integration that is real or potentially embedded in individual social network, able to bring 
benefits to individuals. Social capital has embodied the informal relational network among enterprise colleges, providing channels for the social interaction among them and strengthening their cooperation and mutual trust [7].

As indicated in researchers of Zhang and Gu(2015), Zhong-yong thinking promotes the creativity of employees by affecting their satisfaction [8]. Wang(2015) thinks that the structure, relation and cognition of individual social capital has significant effects on occupational success of knowledgeable employees [9]. Based on their researches, Yuan, He and Peng(2010) reach an conclusion that organizational social capital plays a partially intermediary role in the practice and knowledge sharing of committed human resources [10]. Wu and Lin(2015) divide Zhong-yong thinking into three dimensions namely multipartite thinking, conformity and concordance [11]. It can be inferred from the above literature that Hypothesis 3 and 4 of the research are listed as follows:

H3: Social capital has positive effects on employees survival ability.

H4: Under the influence of Zhong-yong thinking on employees survival ability, social capital plays an mediating role, that is, Zhongyong thinking has positive effects on employees survival ability through social capital.

H4a: Under the influence of multipartite thinking on employees survival ability, social capital plays an mediating role, that is, multipartite thinking has positive effects on employees survival ability through social capital.

H4b: Under the influence of conformity of Zhong-yong thinking on employees survival ability, social capital plays an mediating role, that is, the conformity of Zhong-yong thinking has positive effects on employees survival ability through social capital.

H4c: Under the influence of concordance of Zhong-yong thinking on employees survival ability, social capital plays an mediating role, that is, the concordance of Zhong-yong thinking has positive effects on employees survival ability through social capital.

\subsection{Moderating effect of knowledge sharing behavior}

As indicated in researches of Davenport and Prusak (1998), knowledge sharing develops to new knowledge through constant communication and accumulation of knowledge owners including functions of knowledge transmission and knowledge absorption. By studying organizational knowledge sharing [12], Ipe (2013) has pointed out that knowledge sharing is a whole process in which individuals transfer their own knowledge into those can be understood, absorbed and used by others [13]. Researches of Kostova and Roth(2003) show that knowledge sharing will be affected by multiple aspects of social capital [14]. It can be inferred from the above literature that Hypothesis 5 and 6 of the research are listed as follows:

H5: In the context of knowledge sharing behavior, Zhong-yong thinking has positive moderating effects on social capital; Namely, Zhong-yong thinking has stronger positive effects on social capital as the knowledge sharing behavior increases.

H5a: In the context of knowledge sharing behavior, multipartite thinking has positive moderating effects on social capital; Namely, multipartite thinking has stronger positive effects on social capital as the knowledge sharing behavior increases.

H5b: In the context of knowledge sharing behavior, the conformity has positive moderating effects on social capital; Namely, the conformity has stronger positive effects on social capital as the knowledge sharing behavior increases.

H5c: In the context of knowledge sharing behavior, the concordance has positive moderating effects on social capital; Namely, the concordance has stronger positive effects on social capital as the knowledge sharing behavior increases.

H6: In the context of knowledge sharing behavior, social capital has positive moderating effects on employee survival ability; Namely, social capital has stronger positive effects on employee survival ability as the knowledge sharing behavior increases.

\section{Methodology}

\subsection{Research Framework}

Based on the above mentioned reference, this research has established that Zhong-yong thinking is independent variable and dependent variable employee survival ability. The conceptual framework of this study has been built by introducing social capital (Mediating Variable) and knowledge sharing behavior (Moderating Variable), as shown in Figure 1.

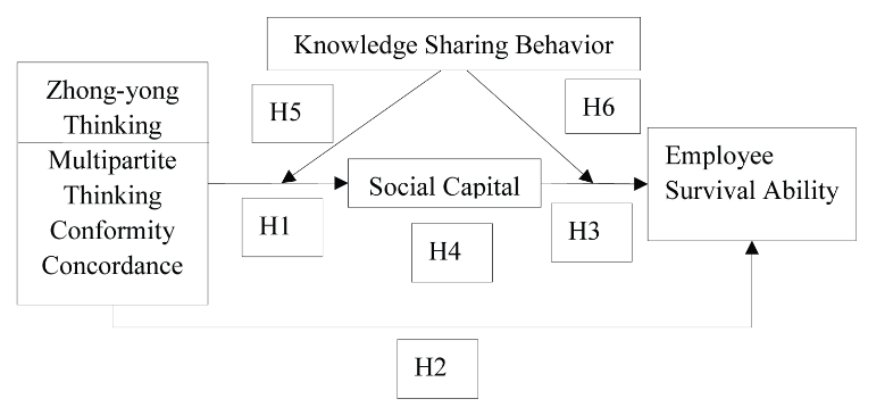

Figure1. Conceptual Framework

\subsection{Issuance and recovery of questionnaires}

Employees have been taken as investigation objects who work in multiple enterprises in various industries of education, finance and fast moving consumer goods.

The method of convenience sampling has been adopted to issue formal questionnaires and forward electronic questionnaires through WeChat QQ Email and other network communication tools. 450 questionnaires are issued in total [15], 65 of which are deleted because of the unavailability and 385 of which are recovered. The recovery rate of effective questionnaires is $85.6 \%$.

\subsection{Methods of data analysis}

Through SPSS 22 and AMOS 21, the research has adopted descriptive statistics analysis, reliability analysis, discriminant validity analysis, convergent validity analysis, correlation analysis and regression analysis to verify the relationship among variables.

\section{Conclusions}

The research has tested the effects of Zhong-yong thinking and social capital on employees survival ability. Results show as follow: (1) The multipartite thinking, conformity and concordance of employees' Zhongyong thinking have positively significant effects on social capital and employees survival ability; (2) Social capital plays a partially mediating role between the multipartite thinking dimension, conformity dimension and concordance dimension of employees' Zhong-yong thinking and employees survival ability; (3) Knowledge sharing behavior has positively moderating effects on multipartite thinking of Zhong-yong and social capital; (4) Knowledge sharing behavior has no moderating effects on the conformity of Zhong-yong thinking and social capital; (5) Knowledge sharing behavior has no moderating effects on the concordance of Zhongyong thinking and social capital; (6) Knowledge sharing behavior has no moderating effects on social capital and employees survival ability.

\section{Suggestions}

Zhong-yong thinking has positive effects on employees survival ability when the Zhong-yong thinking levels of employees are mainly embodied in multiple aspects including multipartite thinking, conformity and concordance. Therefore, the employee survival ability can be strengthened by promoting items as mentioned above.

For enterprise managers, they should think about how to complete personnel training and echelon construction. They should broaden the training path for employees through diversified training methods of teaching style, consulting style, experiencing style and expanding style, thus to provide theoretical and practical supports for employees to ponder over and solve problems related to their survival abilities. Enterprises should negotiate a suitable career planning program together with employees and help them to acquire more working background and experience through internal shifts and exchanges among enterprises, thus to fully inspire their abilities of innovative thinking.

As the theme of today's society, harmony has conformed to the 
requirements of the times. The concordance of Zhong-yong thinking, as an operative norm that is not extreme, helps enterprises to build a harmonious innovation culture. Consequently, enterprises should consider how they can improve the concordance level of employees through a series of measures. During the process, enterprise managers should pay more attention to the flexible management, conducting humanized and contextualized management against different posts.

\section{References}

[1] [8] G. X. Zhang and X. Y. Gu: Zhong-yong thinking and employee creativity. Science Research Management, s1(2015): 251-257.

[2] Y. Shen, Popularity orientation: Interpersonal practice of Zhong-yong thinking - Reconsidering social action orientation mode of Chinese". Journal of Nanjing University (Philosophy, Humanities and Social Sciences), 42.5(2005): 130-137.

[3] [11] J. H. Wu and Y. Z. Lin: The compilation of Zhong-yong thinking scale. Indigenous Psychological Research in Chinese Societies, 24(2005): 247-300.

[4] Q. Q. Li, X. Zhang and X. S. Shang, The management of sinology: The application of confucian management thinking in modern enterprise management. Commercial Times, 33(2013): 106-107.
[5] Q. M. Li and Z. X. Chen: The influence of Zhong-yong thinking on social adoption: The intermediary role of menal resilience and emotional adjustment. Chinese Journal of Ergonomics, 22.1(2016): 11-15.

[6] Burt, R. S. Structural Holes: The Social Structural of Competition. Cambridge: Harvard University Press, 11.2(1992):233-257.

[7] Nahapiet, J., \& Ghoshal, S. Social capital, intellectual capital, and the organizational advantage. Academy of Management Review, 23.2(1998): 242-266.

[9] X. Y. Wang: Research on the Relationship Among Social Capital, Absorptive Ability and Occupational Success of Knowledgeable Employees in High-tech Enterprises (Ph.D., Zhejiang Gongshang University, China, 2015).

[10] Y. Z. Yuan, H. T. He and J. S. Peng: Research on action mechanism of practice and knowledge sharing of committed human resources- An empirical test of intermediary role of organizational social capital. Science of Science and Management of S.\&.T, 31.1(2010): 171-177.

[12] Davenport, T. H., and Prusak, L. Working knowledge : How organizations manage what they know. Harvard Business Press, (1998):1718.

[13] Ipe, M. Knowledge sharing on organizations : A conceptual framework. Human Resource Development Review, 2.4(2003): 337-359.

[14] Kostova, T. and Roth, K. Social capital in multinational corporations and a micro-macro model of its formation. Academy of Management Review, 28.2(2003): 297-317. 